\title{
POTANSİYEL YEŞİL YAKALILARIN YEŞİL FARKINDALIKLARINA YÖNELİK BİR ARAŞTIRMA
}

Barış AKSU 1

Benan YÜCEBALKAN 2
Received Date (Başvuru Tarihi):

Accepted Date (Kabul Tarihi):

Published Date (Yayın Tarihi):
$26 / 08 / 2020$

$9 / 10 / 2020$

$10 / 12 / 2020$

Çalıșmada ilk yazar Sorumlu Yazar (Corresponding Author) rolündedir.

$\ddot{O Z Z}$

\section{Anahtar Kelimeler: \\ Yeşil Yakalılar, \\ Yeşil İşler, \\ Yeşil Farkındalık, \\ Sürdürülebilirlik}

JEL Kodları:

$M$,

$Q$
Sanayi toplumu ve sonrasında mavi yakalı ve beyaz yakalı meslekler ağırlıkta iken, günümüzde bu mesleklerin yanında yeşil yakalı olarak adlandırlan meslekler istihdamda önem kazanmaktadır. Yeşil işler ya da yeşil yakalı meslekler, "Gelecekte dünya ekosistemine zararl olabilecek faaliyetlerden kaçınarak, çevre kalitesini koruyan ve yükselten işler" olarak tanımlanmaktadır. Yeşil işler aynı zamanda, "İşgücüne verimli çalışma ortamları sunan, haklarına duyarlı, kararlara katılım ile yeterli gelir olanakları sağlayan, sosyal koruma sağlayan işler" dir. Yeşil yakalı çalışanlar endüstrinin tüm sektörlerinde hizmet vermektedir. Bu bağlamda gerçekleştirilen çalışmanın amacı, üniversite öğrencilerinden oluşan gelecekteki potansiyel yeşil yakalı çalışanların ve liderlerin çevresel duyarlılık ve farkındalık düzeylerinin tespiti olarak belirlenmiştir. Çalışmanın sonunda katılımcıların genel çevre bilinç oranı ortalaması \% 65,3 \% 11,7 olarak elde edilmiştir. Bununla birlikte, "yeşil kampus $(\% 23,8)$ ", "karbon ayak izi $(\% 19,9)$ " ve "gri sular $(\% 17,2)$ " konularl hakkında katılımcıların çok az farkındalı̆̆a sahip olduğu bulgusuna ulaşılmıştır.

\section{Green Collars Green Jobs Green Awareness Sustainability}

Keywords:

$M$

$Q$

\footnotetext{
${ }^{1}$ Öğr. Gör. Dr., Kocaeli Üniversitesi, barisaksu@yahoo.com,

2 Dr. Öğr. Üyesi, Kocaeli Üniversitesi, byucebalkan@gmail.com,
}

https:// orcid.org/0000-0003-0660-0368 


\section{EXTENDED ABSTRACT}

\section{A RESEARCH ON THE GREEN AWARENESS OF POTENTIAL GREEN}

\section{COLLARS}

\section{LITERATURE}

\subsection{RESEARCH SUBJECT}

Sustainability can generally be defined as "the ability to meet the needs of future generations without compromising the ability to meet current needs" (Cohen et al., 3). When the concept of sustainability is considered in terms of the business world, it can be said that it does not only focus on financial profits but also considers environmental, social and economic impacts in decision processes (Ones \& Dilchert, 2012:450). In this context, the concept of sustainability has brought new professions to working life. While blue-collar and white-collar occupations are predominant in the industrial society and afterwards, the occupations called green-collar gain importance in employment today (Sungur, 2011:154). Green jobs or green-collar jobs are defined as "jobs that protect and increase the quality of the environment by avoiding activities that may be harmful to the world ecosystem in the future" (UNEP et al., 2008:35). Green jobs are also "jobs that provide efficient working environments for the workforce, are sensitive to their rights, provide sufficient income opportunities through participation in decisions, and provide social protection" (ILO, 2013:23).

\subsection{RESEARCH PURPOSE AND IMPORTANCE}

In the background of the employees' attitudes and behaviours to protect the environment, they must have sufficient awareness to protect the environment. Based on this requirement, the aim of the study was determined as the determination of the environmental sensitivity and awareness levels of the university students who are future green-collar employees and leaders.

\subsection{CONTRIBUTION of the ARTICLE to the LITERATURE}

The study will contribute to similar studies on green awareness (environmental awareness) in the literature with different samples.

\section{DESIGN AND METHOD}

\subsection{RESEARCH TYPE}

The study is the applied research conducted with the survey method.

\subsection{RESEARCH PROBLEMS}

Research questions are:

- What is the green awareness (environmental awareness) level of the students?

- Does green awareness (environmental awareness) differ according to the gender of the students?

- Does green awareness (environmental awareness) differ according to the class level of the students?

- Does green awareness (environmental awareness) differ depending on the size of the city students live?

- What are the three most important environmental events or pollution according to the students?

\subsection{DATA COLLECTION METHOD}

In practice, a survey was conducted on 407 university students (in Kocaeli and Sakarya Universities) determined by simple random sampling method, in November and December 2019, to measure the environmental awareness of the participants. Questionnaires were applied face to face.

\subsection{QUANTITATIVE/QUALITATIVE ANALYSIS}

The data obtained in the study were analyzed with the SPSS 21 program. The resulting results are explained with summary tables and graphics. Binomial test, t-test, ANOVA, Chi-square test, Levene Homogeneity Test, Tukey Test were used in the analyzes. The significance level in all tests is $5 \%(p=$ $0.05)$. 


\section{FINDINGS AND DISCUSSION}

\subsection{FINDINGS as a RESULT of ANALYSIS}

At the end of the study, it was determined that there was no significant difference between men and women in terms of green awareness (environmental awareness), and also the size of the city they live in did not reveal a difference. However, the classes of university students participating in the study revealed a difference in terms of their environmental awareness. First-grade students were determined as the group with the lowest environmental awareness. The environmental awareness of the students in the 2nd, third and 4th grades is higher than those in the 1st grade. In the study, the average level of general environmental awareness of the students was obtained as $65.3 \% \pm 11.7 \%$. However, it was determined that they have very little awareness of "green campus $(23.8 \%)$ ", "carbon footprint $(19.9 \%)$ " and "grey waters $(17.2 \%)$ ". When the potential green-collar employees were asked to list the three most important environmental events or pollution, the findings "global warming", "air pollution" and "chemical wastes" were found, respectively.

\subsection{DISCUSSING the FINDINGS with the LITERATURE}

Şenyurt et al. (2011), Altıparmak (2012), Saygılı et al. (2016), Gültekin (2017), Aydın and Toygar (2018) found that female students have higher environmental sensitivity compared to men. However, in the study conducted by Acungil (2020), it was observed that male students have more positive environmental sensitivity and behaviour than female students. However, in the findings obtained from the studies of Kanbak (2015), Arslan and Kızıldağ (2018), it was determined that environmental attitude did not make a difference with gender.

Considering the effects of the education year on green awareness, Aydın and Toygar (2018) found that the environmental awareness of 1st-grade students was higher than the other grade students in the study. However, in the study conducted by Acungil (2020), the average of the positive attitudes of the primary and 1st-grade students towards the environment was lower than the other grades (3rd, fourth and fifth and above). However, Oğuz et al. (2011), Altıparmak (2012), Arslan and Kızıldağ (2018) showed that there was no statistically significant difference in the attitude, awareness and sensitivity of the students towards the classroom and environment they study.

\section{CONCLUSION, RECOMMENDATION AND LIMITATIONS}

\subsection{RESULTS of the ARTICLE}

In conclusion, it can be said that educating students about the environment will be of great importance in raising awareness about the environment because a green economy requires continuous education, development and adaptation skills to meet the changing labour force demands. As in all education, the primary purpose of environmental education should be to create behavioural change in the individual.

\subsection{SUGGESTIONS BASED on RESULTS}

The necessity of determining and implementing interdisciplinary training modules with the cooperation of different institutions and units that are dynamic, continually changing and developing, offering multiple skills and knowledge related to green activity areas may be the suggestion of this study. Another suggestion of the study is to prioritize similar researches and the need to repeat similar studies with different samples on environmental awareness. The proliferation of such studies will be useful in increasing green awareness and determining essential strategies on the environment.

\subsection{LIMITATIONS of the ARTICLE}

The limitation of the study is that the sample consists of Kocaeli University students and Sakarya University students. 


\section{GİRIŞ}

İş dünyasının doğa üzerindeki olumsuz etkileri 70'li yıllardan bu yana bilinmekle birlikte yeterli düzeyde iyileştirmeler gerçekleşememiştir. Oysa sürdürülebilir bir dünyaya giden dönüşüm sürecinin en önemli bileşenlerinden biri iş dünyasıdır. Nitekim Fisk (2010), dünyadaki hiçbir gücün iş dünyasının bu süreçte ortaya koyacağı etkiye sahip olamayacağını ifade etmektedir. Ancak uygulamada işletme çalışanları hem şirketlerinin çevreye verdiği zararlara aracı olmakta, hem de bu zararlardan doğrudan etkilenmektedir.

Sürdürülebilirlik genel olarak "Şu andaki ihtiyaçları karşılama becerisinden ödün vermeden, gelecek kuşakların da ihtiyaçlarını karşılama becerisi" biçiminde tanımlanabilir. Başlangıçta çevresel sürdürülebilirlik için kullanılan terim bugün sosyal ve çevresel etkilerin tüm yönlerini kapsamaktadır (Cohen vd., 3).

Sürdürülebilirlik kavramı iş dünyası açısından ele alındığında, yalnızca finansal kârlar üzerinde odaklanmadığı, aynı zamanda karar süreçlerinde çevresel, sosyal ve ekonomik etkileri göz önünde bulundurduğu söylenebilir. "Triple bottom line" olarak adlandırılan çevresel, sosyal ve ekonomik üç temel alana ithafen şirketler de giderek artan biçimde başarı sütunlarını üç temel alana yöneltmektedir: Kâr, gezegen ve insanlar (Ones \& Dilchert, 2012:450). Sürdürülebilir organizasyon ise eş zamanlı olarak çevresel, sosyal ve ekonomik kârlara katkıda bulunan ve aynı zamanda organizasyonel sürdürülebilirliğini de uzun vadede garanti altına alan girişim olarak tanımlanabilir (Cohen vd., 1). Yâni günümüzde şirketler büyüme ve kâr temel amaçlarının yanında, aldıkları kararlarda toplum ve çevre üzerindeki etkilerinden de sorumlu tutulmaktadır. Bu noktada insan kaynakları şirketlerin karşılaştığı mevcut ve gelecekteki sürdürülebilirlik zorluklarıyla başa çıkabilecek yeteneklerin geliştirilmesinde kilit rol oynamaktadır ve bütüncül bir yaklaşımı benimsemeleri gerekmektedir (Garg, 2014:378).

$\mathrm{Bu}$ çerçevede sürdürülebilirlik kavramı çalışma yaşamına da yeni meslekler kazandırmıştır. Sanayi toplumu ve sonrasında mavi yakalı ve beyaz yakalı meslekler ağırlıkta iken, günümüzde bu mesleklerin yanında yeşil yakalı olarak adlandırılan meslekler istihdamda önem kazanmaktadır (Sungur, 2011:154). Dahası bir adım ileri 
giderek, şirketlerin kaliteli iş gücünü kendilerine çekebilmek için oluşturdukları "işveren markası" ve "itibar yönetimi" ile birlikte artık mavi yakalılar ve beyaz yakalılardan oluşan insan kaynakları döneminin sona eriyor olduğu, yeşil yakalılar devrinin başladığı söylenebilir (kigem.com, 2020).

$\mathrm{Bu}$ bağlamda, çalışanların çevreyi korumaya yönelik tutum ve davranışlar sergilemesinin arka planında öncelikle çevreyi korumaya yönelik yeterli farkındalı̆̆a sahip olmaları gerekmektedir. Bu gereklilikten hareketle çalışmanın amacı, üniversite öğrencilerinden oluşan gelecekteki potansiyel yeşil yakalı çalışanların ve liderlerin çevresel duyarlılık ve farkındalık düzeylerinin tespiti olarak belirlenmiştir.

Araştırma soruları şunlardır:

- Öğrencilerin yeşil farkındalık (çevre bilinci) düzeyi nedir?

- Yeşil farkındalık (çevre bilinci) öğrencilerin cinsiyetine göre farklılık göstermekte midir?

- Yeşil farkındalık (çevre bilinci) öğrencilerin okudukları sınıf düzeyine göre farklılık göstermekte midir?

- Yeşil farkındalık (çevre bilinci) öğrencilerin yaşadıkları şehrin büyüklüğüne göre farklılık göstermekte midir?

- Öğrencilere göre en önemli üç çevre olayı veya kirliliği nedir?

\section{LITERATÜR}

Literatür çalışması kavramsal temeller ile daha önce yapılmış uygulamalı araştırmalardan oluşan iki başlık altında toplanmıştır.

\subsection{Kavramsal Temeller}

Dünya genelinde ekonomik dengeler ve istihdam stratejileri sürdürülebilirlik, kurumsal sosyal sorumluluk, yenilenebilir enerji kaynakları ve çevre korumacılığı gibi temel değerler etrafında yeniden tanımlanmaktadır. Bu yeniden yapılanma süreci şirketler ve toplumlar üzerinde önemli değişimlere yol açmaktadır. Değişimlerin kalbinde konumlanan insan ve dolayısıyla insan kaynaklarını da bu kavram ve olgulardan bağımsız düşünmek olanaklı değildir. Dolayısıyla yapılan iş veya 
bulunulan pozisyon ne olursa olsun, bu değerleri yaşam ve iş felsefesinin merkezine koyan ve yürütmekte olduğu çalışmalarda bu tutum ve yaklaşımı ön planda tutan çalışanlar "yeşil yakalılar” olarak tanımlanabilir (kigem.com, 2020).

"Yeşil yakalı işçi" terimi yeşil, sürdürülebilir veya çevresel işlerde çalışanları tanımlamak amacıyla giderek daha fazla kullanılmakla birlikte terimin standart bir tanımı yoktur.

En geniş tanım ABD yeşil danışmanlık kuruluşu Viridus'a aittir. Kurucuları Furqan Nazeeri ve Mike Di Pietro, "Herkes yeşil yakalı bir işe sahiptir. Kartvizitlerinde 'çevre', 'sürdürülebilir', 'yeşil' veya benzeri terimleri taşıyan herkes yeşil yakalıdır' demektedirler. San Francisco State University'de kentsel çalışmalar (Urban Studies) Profesörü Raquel Rivera Pinderhughes'e göre de: “Yeşil yakalı işler, ürünleri ve hizmetleri çevre kalitesini doğrudan artıran işletmelerdeki yâni yeşil işletmelerdeki mavi yakalı işlerdir". Avustralya Koruma Vakfı (The Australian Conservation Foundation) ise, "Yeşil işler veya yeşil yakalı işler daha iyi çevresel sonuçlara veya sürdürülebilirliğin artışına katkıda bulunur. Yeşil yakalı işler düşük beceriden, giriş seviyesi pozisyonlarından yüksek beceriye, daha yüksek ücretli işlere ve hem becerilerde hem de ücretlerde ilerleme fırsatlarını içerir." tanımlamasıyla endüstri ya da mesleğe değil, beceri düzeyine vurgu yaparak yeni bir bakış açısı getirmektedir (Connection Research [cr], 2009:8, 10). Diğer yanda Jones (2008), “yeşil yakalı"daki "yeşil” in çevre kalitesinin korunması ve geliştirilmesi ile ilgili olduğunu belirtmekle (Gregson, 2010:119) birlikte, sürdürülebilirliği benimseyen birçok çevreci ve eğitimcinin aksine Jones (2008) ve Hawkin (2007) yeşil yakalı çalışmanın çevre kirliliği ile mücadelenin yanı sıra yoksullukla mücadele ile de ilgili olduğunu; ekonomik ve sosyal adaletsizliğin çevresel sömürü ve bozulma ile bütünleşik biçimde ilişkili olduğunu ileri sürmektedirler. Dolayısıyla yeşil yakalı işgücünün gelişimi aynı zamanda iyi ücretler, eşit fırsatlar, başarı ve yeni iş yaratma anlamlarına da gelmektedir (Gregson, 2010:120).

Birleşmiş Milletler Çevre Programı (United Nations Environment Program [UNEP]) yeşil yakalı işleri hem endüstri hem de meslek açısından tanımlamaktadır. UNEP/ILO/IOE/ITUC (2008)'in “Yeşil İşler: Sürdürülebilir Düşük Karbonlu Bir 
Dünyada İnsana Yakışır İşe Doğru" (Green Jobs: Towards Decent Work in a Sustainable Low-Carbon World) başlıklı raporunda yeşil işler ya da yeşil yakalı meslekler, "Gelecekte dünya ekosistemine zararlı olabilecek faaliyetlerden kaçınarak, çevre kalitesini koruyan ve yükselten işler" olarak tanımlanmaktadır (UNEP vd., 2008: 35). Bu işler tarım, imalat, inşaat, kurulum ve bakımdaki bilimsel, teknik, idari ve hizmetle ilgili faaliyetlerin yanı sıra çevre kalitesinin korunmasına veya eski haline getirilmesine önemli ölçüde katkıda bulunan pozisyonlardır. Yeşil işlerin,

- biyolojik çeşitliliği ve ekosistemi koruması,

- enerji, su ve malzeme tüketimini düşürmesi,

- ekonomik faaliyetlerde düşük karbon kullanılması,

- atık ve kirlilik üretimini minimuma indirmesi ve/veya önlemesi

gibi temel özellikleri bulunmaktadır (UNEP vd., 2008: 35, 36).

Uluslararası Çalışma Örgütü (International Labour Organization [ILO])'ne göre de yeşil işler aynı zamanda, “İşgücüne verimli çalışma ortamları sunan, haklarına duyarlı, kararlara katılım ile yeterli gelir olanakları sağlayan, sosyal koruma sağlayan işler” dir (ILO, 2013: 23). ILO'nun kapsamlı tanımına göre bir iş “Enerji ve doğal kaynaklardan tasarruf eden, yenilenebilir enerji kullanan, çevre ve hava kirliliğine yol açmayan, biyo-çeşitliliği koruyan, sürdürülebilir üretime katkı sağlayan” bir iş ise yeşil iştir; yeşil işler yalnızca çevre koruma sektörleriyle ilgili değildir (Sungur, 2011: 154). Ayrıca ILO 21. yy. için iki temel sorunla mücadele ettiğini belirtmektedir. Bunlardan ilki, zararlı iklim değişikliğinin şimdiki ve gelecek kuşakların yaşam kalitesini ciddi şekilde tehlikeye atacağı gerçeği ve doğal kaynakların bozulması; ikincisi de yoksulluk ve işsizliktir (Başol, 2013:1).

Yeşil yakalıların karakteristikleri şöyle sıralanabilir (Harvey vd., 2010:501; Connection Research, 2009:9):

- Kâğ1t, cam, plastik gibi evsel atıkları geri dönüştüren,

- Evinde enerji tasarrufu değişiklikleri yapan,

- Çevreye zararlı ürünleri kullanmaktan kaçınan, 
- Geleceğin enerji tasarruflu teknolojisiyle ilgilenen,

- Olanaklıysa geri dönüşüm işlerinde çalışan,

- İş yerinde kağıtlları geri dönüştüren,

- İş yerinde yeşil IT için kampanya yürüten,

- Enerji tasarrufuna yönelik (Güneş enerjisi, rüzgâr enerjisi gibi) teknolojilerin işyerinde ve çevresinde kullanımını teşvik eden,

- Çevre konularıla ilgili (Greenpeace vb.) bir organa veya kuruluşa üye olan,

- Çevreyle ilgili sivil toplum kuruluşlarına para desteği sağlayan,

- Başkalarını yukarıdakilerin bir kısmını veya tamamını yapmaya teşvik eden.

"Yeşil yakalı" işgücü, ABD'de ve dünya genelinde kendine özgü ve hızla gelişen çalışanları ifade etmektedir. "Yeşil" işler ise sürdürülebilirliği artırmak, atık, enerji kullanımı ve kirliliği azaltmakla ilgili görevleri içermektedir. Örneğin profesyoneller (çevre danışmanları, yeşil bina mimarları, çevre, sistem veya nükleer mühendisleri, çevre avukatı vb.), imalat ve inşaat sektörlerinde çalışanlar (güneş paneli tesisatçıları, yeşil binalar ve yenilenebilir enerji santralleri için inşaat işçileri veya fabrikalarda yeşil binalar için malzeme üreten işçiler vb.) gibi. Ayrıca atık yönetimi, tehlikeli maddelerin temizlenmesi ve geri dönüşüm işleri yeşil yakalı işgücünün bir diğer sınıflandırmasıdır. Diğer örnekler arasında organik çiftçiler, çevre eğitimcileri, toplu taşıma çalışanları ve yeşil araç mühendisleri sayılabilir (Mc Clure vd., 2017:440).

Görüldüğü üzere yeşil işler, yeni yaratılan işlerin yanı sıra mevcut işlerin hem çevre hem de çalışanlar üzerindeki etkilerini artırmak için gerçekleştirilen "yeşillendirme" yi de kapsamaktadır. Yeşil yakalı çalışanlar ise endüstrinin tüm sektörlerinde hizmet vermektedir. Bu bağlamda, yakın geleceğin yeşil yakalı çalışanları olacak olan üniversite öğrencileri, bu çalışmada potansiyel yeşil yakalılar olarak adlandırılmış ve çevreyi korumaya yönelik tutum ve davranışlar sergilemelerinin arka planında öncelikle yeterli yeşil farkındalığa (çevre bilincine) sahip olmaları gerektiği vurgusu yapılmıştır. 


\subsection{Uygulamalı Araştırmalar}

Yükseköğretim kurumlarında öğrenim gören potansiyel yeşil yakalı öğrencilere yönelik yeşil farkındalık (çevre bilinci) hakkında daha önce gerçekleştirilen çalışmalarda özellikle cinsiyetin ve eğitim yılının farkındalık üzerindeki etkileri üzerinde durulmuştur.

Şenyurt vd. (2011), Altıparmak (2012), Saygılı vd. (2016), Gültekin (2017), Aydın ve Toygar (2018)'ın gerçekleştirdikleri çalışmalarda kadın öğrencilerin erkeklere göre çevresel duyarlılıklarının yüksek olduğu tespit edilmiştir. Ancak Acungil (2020)'in gerçekleştirdiği çalışmada erkek öğrencilerin kadın öğrencilere göre daha olumlu çevresel duyarlılık ve davranışa sahip olduğu gözlenmiştir.

Bununla birlikte, Kanbak (2015), Arslan ve Kızılda ğ (2018)'ın araştırmalarından elde edilen bulgularda çevresel tutumun cinsiyet ile farklılık yaratmadığı tespit edilmiştir.

Eğitim yılının yeşil farkındalık üzerinde etkileri ele alındığında ise, Aydın ve Toygar (2018)'ın gerçekleştirdiği araştırmada 1. sınıf öğrencilerinin çevresel duyarlılı̆̆ının diğer sınıf öğrencilerinden daha yüksek olduğu tespit edilmiştir. Ancak Acungil (2020)'in gerçekleştirdiği çalışmada hazırlık ve 1. sınıf öğrencilerinin çevreye yönelik olumlu yaklaşımlarının ortalamaları diğer sınıflara (3., 4 . ve 5 ve üzeri) göre daha düşük çıkmıştır.

Bununla birlikte Oğuz vd. (2011), Altıparmak (2012), Arslan ve Kızıldağ (2018)'ın araştırmalarından elde edilen bulgularda, öğrencilerin okudukları sınıf ve çevreye karşı olan tutum, farkındalık ve duyarlılıkları konusunda istatistiksel olarak anlamlı bir farklılık olmadığı görülmüştür.

\section{METODOLOJí}

Uygulamada basit rassal örnekleme yöntemiyle belirlenen 407 üniversite öğrencisi (Kocaeli ve Sakarya Üniversitelerinde) üzerinde, 2019 yılı Kasım ve Aralık aylarında, anket uygulaması yapılarak katılımcıların çevre bilinci düzeyi ölçülmeye çalışılmıştır. Veri toplama zamanı 1 Ocak 2020'den önce olduğundan, etik kurul izin belgesi gerekmemiştir. Anketler yüz yüze uygulanmıştır. Elde edilen veriler SPSS 21 
programıla analiz edilmiştir. Ortaya çıkan sonuçlar özet tablo ve grafiklerle açıklanmıştır. Analizlerde Binomial Test, t-Test, ANOVA, Ki-kare Testi, Levene Homojenlik Testi, Tukey Testi kullanılmıştır. Tüm testlerde anlamlılık seviyesi \%5 $(p=0,05)^{\prime}$ dir.

\section{BULGULAR}

Potansiyel yeşil yakalı çalışanların şu anki çevre bilinci düzeyinin belirlenmesi için yapılan çalışmada elde edilen bulgular aşağıda gösterilmiştir. 407 üniversite öğrencisi üzerinde yapılan ankette, çalışmaya katılanların demografik dağılımları Tablo 1'de verilmiştir.

Şehir büyüklüğünün belirlenmesi aşamasında, nüfus kriteri baz alınarak, İstatistiki Bölge Birimleri Sinıflaması - İBBS (Nomenclature of Territorial Units for Statistics [NUTS]) düzeyleri kullanılmıştır (Şengül vd., 2013:77). Buna göre şehirler alt nüfus 150 bin, 800 bin ve 3 milyon olacak şekilde gruplara ayrılarak incelenmiştir.

Tablo 1. Demografik Yap1

\begin{tabular}{|cc|cc|}
\cline { 3 - 4 } \multicolumn{1}{c}{} & K & $\%$ \\
\hline Cinsiyet & Kadın & 292 & 71,7 \\
& Erkek & 115 & 28,3 \\
\hline \multirow{2}{*}{ Sinıf } & 1 & 112 & 27,5 \\
& 2 & 237 & 58,2 \\
& 3 & 50 & 12,3 \\
& 4 & 8 & 2,0 \\
\hline Şehir & Küçük $(>150$ b) & 35 & 8,7 \\
Büyüklüğü & Orta $(800 \mathrm{~b}-3 \mathrm{~m})$ & 202 & 50,1 \\
& Büyük $(>3 \mathrm{~m})$ & 166 & 41,2 \\
\hline
\end{tabular}

Kaynak: Yazarlar tarafından üretilmiştir.

Üniversite öğrencilerinin çevre bilinci düzeyinin belirlenmesi amacıyla sorulan 16 adet soru ve verilen cevapların dağılımı Tablo 2'de yer almaktadır. İkili yanıt seçeneğine göre verilen yanıtlara Binomial Testi uygulanmış ve çıkan sonuçlar tabloda gösterilmiştir. Buna göre, katılımcıların iki nokta haricinde çevre bilinci bakımından bir farkındalığa sahip olduğu görülmektedir $(p<0,05)$. Bu iki nokta ise "Ülkemize termik santral kurulmasının doğru bir fikir olduğunu düşünüyor musunuz?" ve “Görsel ve yazılı medyada çevre ile ilgili çıkan haberler çevre bilinci oluşturabilmekte midir?" sorularına verilen yanıtlarda ortaya çıkmaktadır $(p>0,05)$. Bu sorulara verilen 
yanıtlarda katılımcıların durumdan emin olamadıkları görülmektedir. Bilinç oranının

her faktöre göre hesaplandığı tabloda, katılımcıların genel çevre bilinç oranı

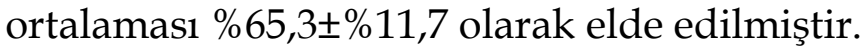

Tablo 2. Çevre Bilinci Düzeyinin Faktörlere Göre Dağılımı

\begin{tabular}{|c|c|c|c|c|c|c|c|}
\hline & \multicolumn{2}{|c|}{ Evet } & \multicolumn{2}{|c|}{ Hayır } & \multicolumn{2}{|c|}{ Bilinç Oranı (\%) } & \multirow[b]{2}{*}{$\mathrm{p}^{*}$} \\
\hline & $\mathbf{n}$ & $\%$ & $\mathbf{n}$ & $\%$ & Ort & $\mathbf{s}$ & \\
\hline $\begin{array}{l}\text { Çevrenin kirletilmemesi için elinizden gelen gayreti } \\
\text { gösterir ve çevrenizdekileri bilinçlendirir misiniz? }\end{array}$ & 388 & 95,3 & 19 & 4,7 & 95,3 & 21,1 & 0,000 \\
\hline $\begin{array}{l}\text { Enerji tasarrufunu sürdürülebilir bir çevre için gerekli } \\
\text { görüyor musunuz? }\end{array}$ & 388 & 95,3 & 19 & 4,7 & 95,3 & 21,1 & 0,000 \\
\hline $\begin{array}{l}\text { Toplu taşıma araçlarının tercih edilmesinin } \\
\text { sürdürülebilir çevre açısından önemli olduğunu } \\
\text { düşünüyor musunuz? }\end{array}$ & 356 & 87,5 & 51 & 12,5 & 87,5 & 33,1 & 0,000 \\
\hline $\begin{array}{l}\text { Yeni araçlar karbon salınımını azaltmak için petrol } \\
\text { ürünlerini yakıt olarak kullanmamaktadır. Bir araç } \\
\text { alacak olsanız öncelikli tercihiniz hibrid/elektrikli } \\
\text { araçlardan yana olur mu? }\end{array}$ & 287 & 70,5 & 120 & 29,5 & 70,5 & 45,7 & 0,000 \\
\hline $\begin{array}{l}\text { Ülkemize termik santral kurulmasının doğru bir fikir } \\
\text { olduğunu düşünüyor musunuz? }\end{array}$ & 198 & 48,6 & 209 & 51,4 & 51,4 & 50,0 & 0,620 \\
\hline Karbon ayak izi hakkında bilginiz var mı? & 81 & 19,9 & 326 & 80,1 & 19,9 & 40,0 & 0,000 \\
\hline Sera etkisi konusunda bir bilginiz var mı? & 255 & 62,7 & 152 & 37,3 & 62,7 & 48,4 & 0,000 \\
\hline Gri sular hakkında bilginiz var mı? & 70 & 17,2 & 337 & 82,8 & 17,2 & 37,8 & 0,000 \\
\hline Yeşil Kampüs hakkında bilginiz var mı? & 97 & 23,8 & 310 & 76,2 & 23,8 & 42,7 & 0,000 \\
\hline $\begin{array}{l}\text { Faturalarınızı elektronik ortamda almanın } \\
\text { sürdürülebilir çevre açısından gerekli olduğunu } \\
\text { düşünüyor musunuz? }\end{array}$ & 340 & 83,5 & 67 & 16,5 & 83,5 & 37,1 & 0,000 \\
\hline $\begin{array}{l}\text { Yenilenebilir enerji kaynaklarının kullanımının } \\
\text { yaygınlaştırılmasının sürdürülebilir bir çevre açısından } \\
\text { gerekli görüyor musunuz? }\end{array}$ & 388 & 95,3 & 19 & 4,7 & 95,3 & 21,1 & 0,000 \\
\hline $\begin{array}{l}\text { Sürdürülebilir bir çevre için gençlerin iyi bir çevre } \\
\text { bilincine sahip olması gerektiğini düşünüyor musunuz? }\end{array}$ & 386 & 94,8 & 21 & 5,2 & 94,8 & 22,1 & 0,000 \\
\hline $\begin{array}{l}\text { Çevre bilinci kazanmanızı sağlayacak herhangi bir proje } \\
\text { ya da seminerde yer aldını mı? }\end{array}$ & 161 & 39,6 & 246 & 60,4 & 39,6 & 49,0 & 0,000 \\
\hline $\begin{array}{l}\text { Çevre bilinci ile ilgili bir dersin tüm üniversite } \\
\text { öğrencileri için zorunlu olması gerekli midir? }\end{array}$ & 323 & 79,4 & 84 & 20,6 & 79,4 & 40,5 & 0,000 \\
\hline $\begin{array}{l}\text { Ülkemizde çevre ile ilgili faaliyet gösteren kamu ve sivil } \\
\text { toplum kuruluşlarının çalışmalarının yeterli olduğunu } \\
\text { düşünüyor musunuz? }\end{array}$ & 83 & 20,4 & 324 & 79,6 & 79,6 & 40,3 & 0,000 \\
\hline $\begin{array}{l}\text { Görsel ve yazılı medyada çevre ile ilgili çıkan haberler } \\
\text { çevre bilinci oluşturabilmekte midir? }\end{array}$ & 208 & 51,1 & 199 & 48,9 & 48,9 & 50,0 & 0,692 \\
\hline
\end{tabular}

* Binomial Test uygulanmıştır.

Kaynak: Yazarlar tarafından üretilmiştir.

Tablo 2' de sunulan her soru için katılımcıların bilinç düzeyleri yüzde (\%) olarak da belirlenmiştir. Buna göre, en çok bilinçli olunan konular sırasıyla; "Enerji tasarrufunu sürdürülebilir bir çevre için gerekli görme $(\% 95,3)$ ”, “Yenilenebilir enerji kaynaklarının kullanımının yaygınlaştırılmasının sürdürülebilir bir çevre açısından gerekli görme $(\% 95,3)$ ”, "Çevrenin kirletilmemesi için gayret gösterme ve çevredekileri bilinçlendirme $(\% 95,3)$ ” ile “Sürdürülebilir bir çevre için gençlerin iyi bir 
çevre bilincine sahip olması gerekliliği $(\% 94,8)$ " şeklinde sıralanmıştır (Şekil 1). Bununla birlikte, “yeşil kampus $(\% 23,8)$ ”, “karbon ayak izi $(\% 19,9)$ ” ve "gri sular $(\% 17,2)$ " konuları hakkında katılımcılar çok az bilince sahiptir.

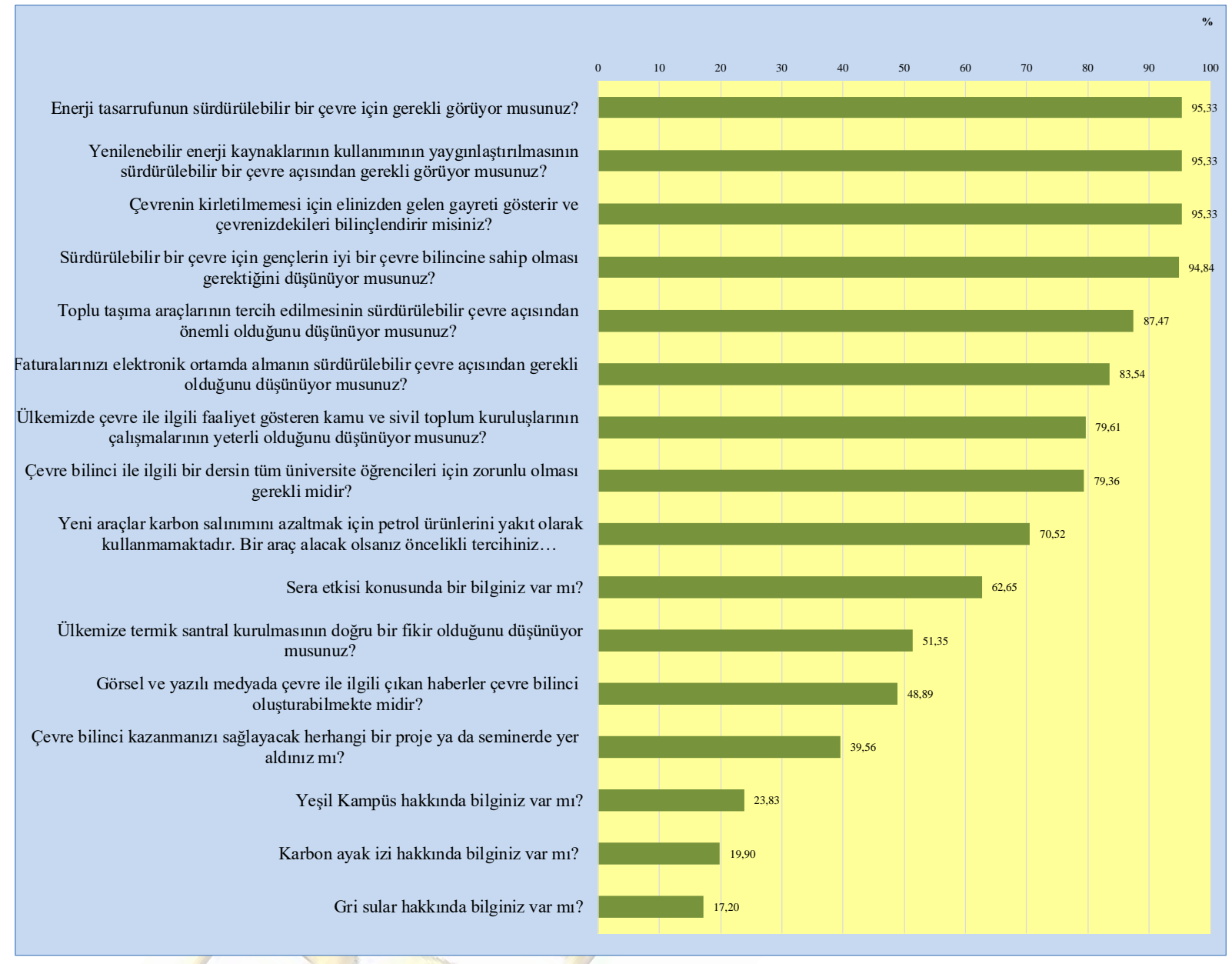

Şekil 1. Çevre Bilinci Düzeyinin Faktörlere Göre Sıralanışı

Kaynak: Yazarlar tarafından üretilmiştir.

Bilinç oranının demografik yapıya göre oluşturduğu farklılıkların incelenmesi için t-Test ve ANOVA'dan yararlanılmıştır. Post-Hoc Testleri (Tukey Testi) kullanılarak maddeler arasındaki farklılıklar belirlenmeye çalışılmıştır. Elde edilen sonuçlar Tablo 3'de ve Şekil 2'de özetlenmiştir. Buna göre, çevre bilinci bakımından kadın ve erkekler arasında anlamlı bir farklılık yoktur $(p=0,814>0,05)$. Ayrıca, katılımcıların yaşadıkları şehrin büyüklüğü de bilinç oranında bir farklılık ortaya çıkarmamaktadır $(p=0,628>0,05)$. Ancak, çalışmaya katılan üniversite öğrencilerinin bulundukları sınıflar çevre bilinçleri bakımından bir farklılık ortaya koymaktadır $(p=0,000)$. Birinci sınıfta okuyanlar çevre bilinci bakımından en düşük orana sahip 
grup olarak belirlenmiştir. 2, 3 ve 4 . sınıftakilerin 1. sınıftakilere göre çevre farkındalığ1 daha yüksektir.

Tablo 3. Bilinç Oranının Demografik Yapıya Göre Oluşturduğu Farklılık

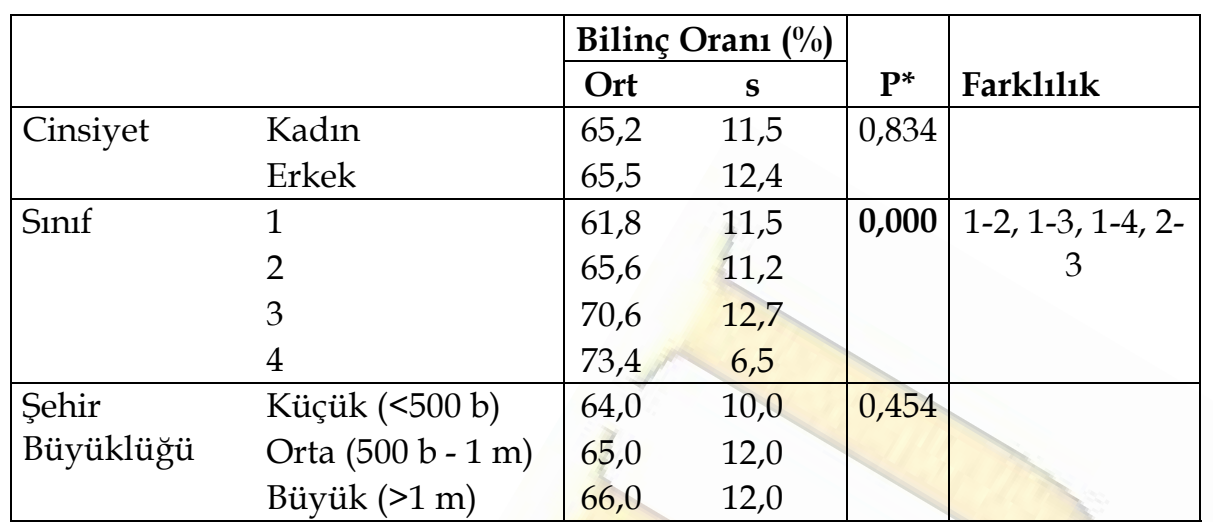

* ANOVA ve t-Test uygulanmıştır. Kaynak: Yazarlar tarafından üretilmiştir.

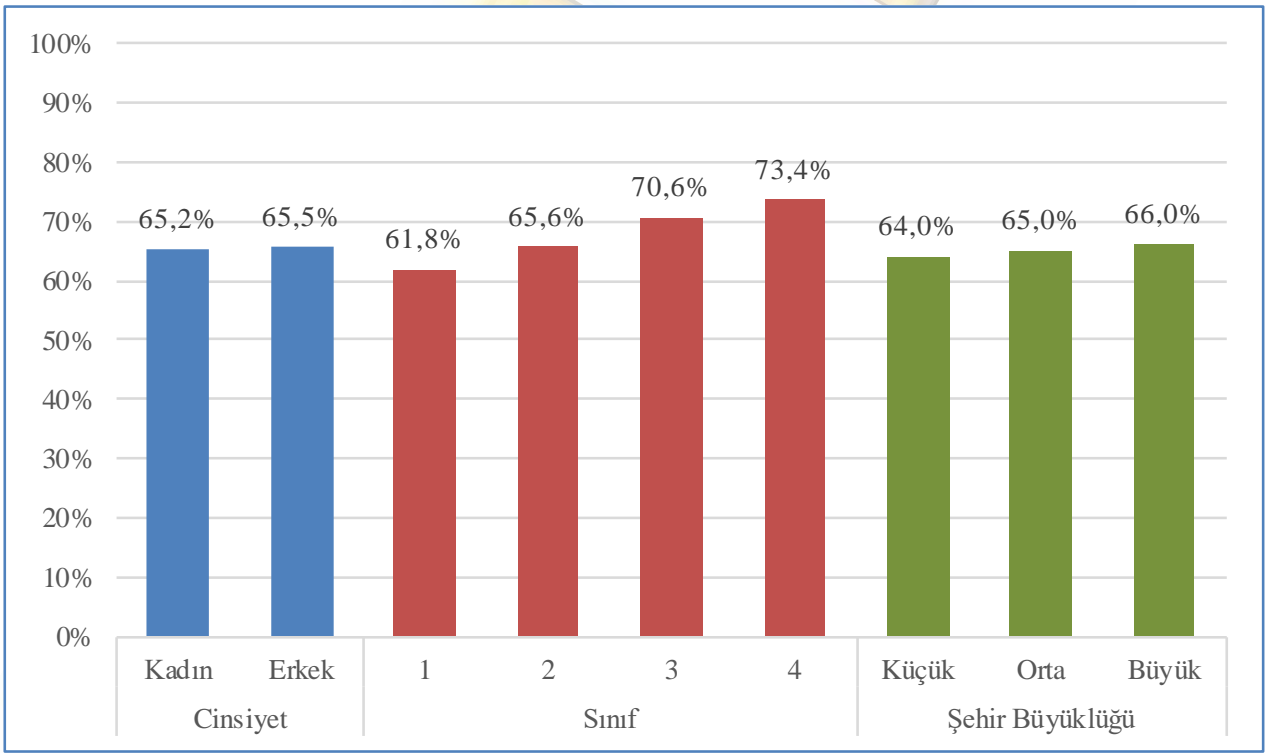

Şekil 2. Bilinç Oranının Demografik Yapıya Göre Oluşturduğu Farklılık

Kaynak: Yazarlar tarafından üretilmiştir.

Çalışmaya katılanlara "Sizce en önemli 3 çevre olayı ya da çevre kirliliği aşağıdakilerden hangisidir?" şeklinde bir soru sorulmuş ve verilen seçeneklerden 3 tanesini (en önemli 1 olacak şekilde) sıralamaları istenmiştir. Toplanan verilerin dağılımı ve sıralaması Tablo 4'de gösterilmektedir. Sıralamanın belirlenmesi için birinci tercihe 3 puan, ikinci tercihe 2 puan ve üçüncü tercihe 1 puan katsayısı 
uygulanmıştır (Örn. Küresel 1sınma için, $171^{*} 3+32^{*} 2+24^{*} 1=601$ ). Böylece her madde için toplam sıralama puanı elde edilmiştir.

Tablo 4. En Önemli Çevre Olayı veya Kirliliği Sıralaması

\begin{tabular}{|c|c|c|c|c|c|c|c|}
\hline & \multicolumn{6}{|c|}{ Tercih Sirası } & \multirow{3}{*}{$\begin{array}{c}\text { Siralama } \\
\text { Puanı }\end{array}$} \\
\hline & \multicolumn{2}{|c|}{1} & \multicolumn{2}{|c|}{2} & \multicolumn{2}{|c|}{3} & \\
\hline & $\mathrm{n}$ & $\%$ & $\mathrm{n}$ & $\%$ & $\mathrm{n}$ & $\%$ & \\
\hline Küresel Isınma & 171 & 75,3 & 32 & 14,1 & 24 & 10,6 & 601 \\
\hline Hava Kirliliği & 58 & 36,3 & 62 & 38,8 & 40 & 25,0 & 338 \\
\hline Kimyasal atıklar & 41 & 24,7 & 56 & 33,7 & 69 & 41,6 & 304 \\
\hline Su kaynaklarının kirletilmesi & 37 & 24,5 & 61 & 40,4 & 53 & 35,1 & 286 \\
\hline Ormanların tahrip edilmesi & 35 & 22,6 & 52 & 33,5 & 68 & 43,9 & 277 \\
\hline $\begin{array}{l}\text { Doğal dengenin bozulması ve kaynak } \\
\text { israfı }\end{array}$ & 19 & 16,0 & 43 & 36,1 & 57 & 47,9 & 200 \\
\hline Evsel Atıklar (Çöp) & 26 & 27,1 & 37 & 38,5 & 33 & 34,4 & 185 \\
\hline Çarpık Kentleşme & 12 & 22,2 & 19 & 35,2 & 23 & 42,6 & 97 \\
\hline Gürültü & 13 & 38,2 & 16 & 47,1 & 5 & 14,7 & 76 \\
\hline Sera Gazları & 10 & 28,6 & 11 & 31,4 & 14 & 40,0 & 66 \\
\hline Görüntü kirliliği & 1 & 5,0 & 10 & 50,0 & 9 & 45,0 & 32 \\
\hline Diğer & 1 & 25,0 & 0 & 0,0 & 3 & 75,0 & 6 \\
\hline
\end{tabular}

Kaynak: Yazarlar tarafından üretilmiştir.

Yapılan sıralamaya göre potansiyel yeşil yakalı çalışanlar en önemli 3 çevre olayını veya kirliliğini sırasıyla "küresel ısınma", hava kirliliği" ve "kimyasal atıklar" olarak belirlemişlerdir (Şekil 3).

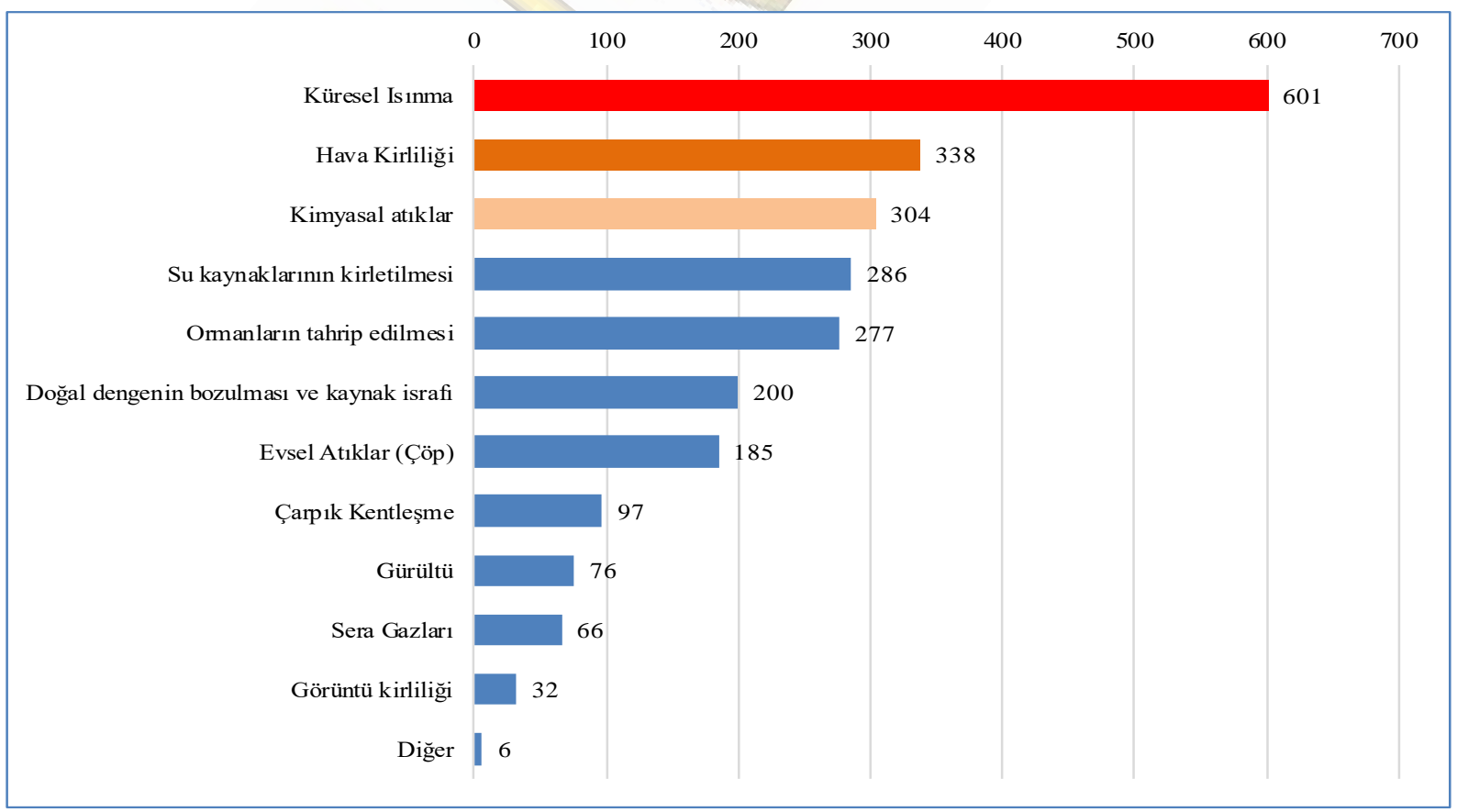

Şekil 3. En Önemli Çevre Olayı veya Kirliliği Sıralaması

Kaynak: Yazarlar tarafından üretilmiştir. 
Geri dönüşümün neden önemli olduğuna dair bilgileri sorgulanan katılımcıların en fazla tercih ettiği cevap "Doğal kaynakların korunmasını sağlar" yönünde olmuştur. Bunu takip eden sırada "Çevre kirliliğinin önlenmesini sağlar" ve "Enerji tasarrufu sağlar" maddeleri yer almaktadır. Tüm tercih değerlerine ait dağılımlar ve önem sıralaması Tablo 5'te ve Şekil 4'te gösterilmektedir.

Tablo 5. Geri Dönüşümün Neden Önemli Olduğuna Dair Önem Siralamas1

\begin{tabular}{|c|c|c|c|c|c|c|c|}
\hline & \multicolumn{6}{|c|}{ Tercih Sirası } & \multirow{3}{*}{$\begin{array}{c}\text { Siralama } \\
\text { Puanı }\end{array}$} \\
\hline & \multicolumn{2}{|c|}{1} & \multicolumn{2}{|c|}{2} & \multicolumn{2}{|c|}{3} & \\
\hline & & $\%$ & $\mathrm{n}$ & $\%$ & $\mathrm{n}$ & $\%$ & \\
\hline Doğal kaynakların korunmasını sağlar & 202 & 59,1 & 94 & 27,5 & 46 & 13,5 & 840 \\
\hline Çevre kirliliğinin önlenmesini sağlar & 123 & 35,1 & 120 & 34,3 & 107 & 30,6 & 716 \\
\hline Enerji tasarrufu sağlamamıza yardım eder & 44 & 16,0 & 93 & 33,8 & 138 & 50,2 & 456 \\
\hline Atık miktarını azaltarak çöp işlemlerinde kolaylık sağlar & 32 & 24,1 & 57 & 42,9 & 44 & 33,1 & 254 \\
\hline Katı atık depolama alanları daha uzun süreli kullanılabilir & 9 & 17,3 & 13 & 25,0 & 30 & 57,7 & 83 \\
\hline Diğer & 5 & 55,6 & 0 & 0,0 & 4 & 44,4 & 19 \\
\hline
\end{tabular}

Kaynak: Yazarlar tarafından üretilmiştir.

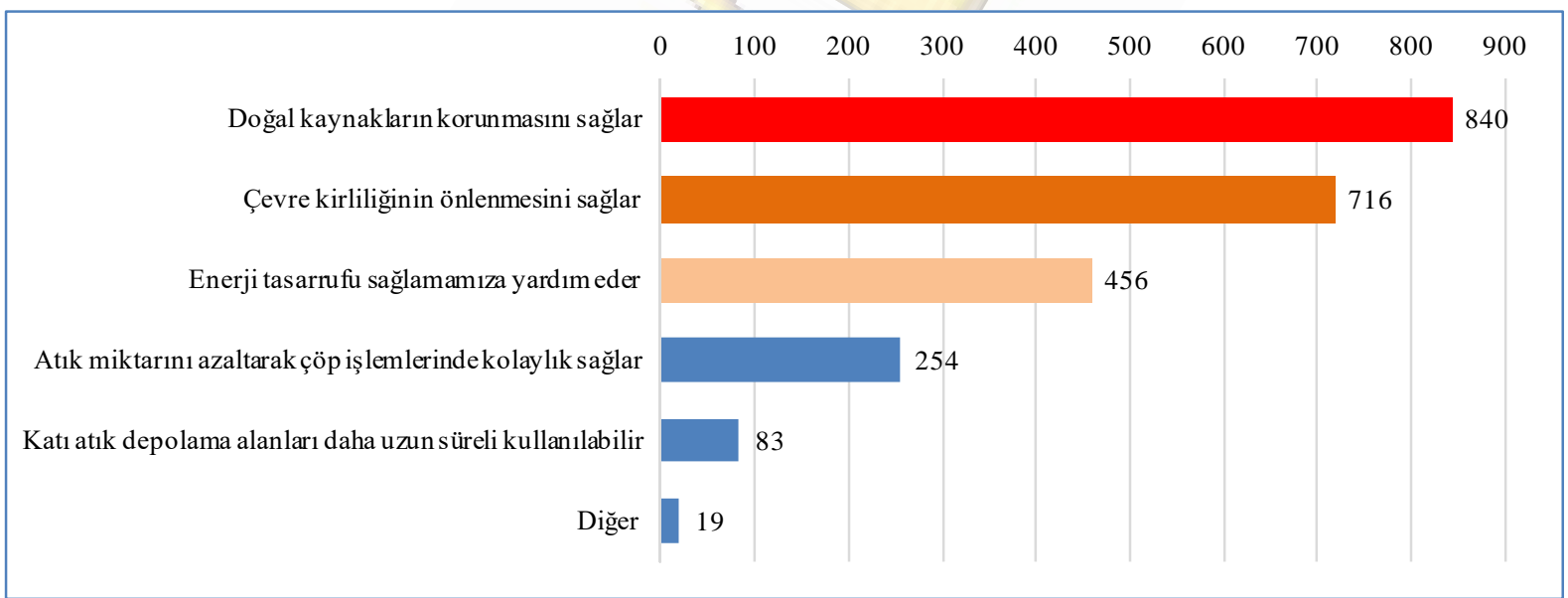

Şekil 4. Geri Dönüşümün Neden Önemli Olduğuna Dair Önem Sıralaması

Kaynak: Yazarlar tarafından üretilmiştir.

\section{SONUÇ}

Çalışmanın sonunda yeşil farkındalık (çevre bilinci) bakımından kadın ve erkekler arasında anlamlı bir farklılık olmadı̆̆ı, ayrıca yaşadıkları şehrin büyüklüğünün de farklılık ortaya çıkarmadığı tespit edilmiştir. Ancak, çalışmaya katılan üniversite öğrencilerinin bulundukları sınıflar çevre bilinçleri bakımından bir 
farklılık ortaya koymuştur. Birinci sınıfta okuyanlar çevre bilinci bakımından en düşük orana sahip grup olarak belirlenmiştir. 2, 3 ve 4. sınıftakilerin 1. sınıftakilere göre çevre farkındalı̆̆ı daha yüksektir.

Araştırmada öğrencilerin genel çevre bilinç oranı ortalaması $\% 65,3 \pm \% 11,7$ olarak elde edilmiştir. Bununla birlikte, "yeşil kampus $(\% 23,8)$ ", "karbon ayak izi $(\% 19,9)$ " ve "gri sular $(\% 17,2)$ " konuları hakkında çok az farkındalığa sahip oldukları tespit edilmiştir. Potansiyel yeşil yakalı çalışanların en önemli üç çevre olayını veya kirliliğini sıralamaları istendiğinde ise, sırasıyla "küresel ısınma", "hava kirliliği" ve "kimyasal atıklar" bulgusuna ulaşılmıştır.

Sonuç olarak, yeşil ekonominin değişen işgücü taleplerini karşılayabilmesi için sürekli eğitim, gelişme ve uyum becerisi gerektiği gerçekliğinden hareketle öğrencilerin çevre hakkında eğitilmesinin çevreye yönelik farkındalık geliştirmelerinin sağlanmasında büyük önem taşıyacağı söylenebilir. Her eğitimde olduğu gibi çevre eğitiminde de temel amaç, bireyde davranış değişikliği oluşturabilmek olmalıdır. Bu çerçevede yeşil faaliyet alanları ile ilgili dinamik, sürekli değişim ve gelişim gösteren, çoklu beceri ve bilgi sunan, farklı kurum ve birimlerin iş birliği ile disiplinler arası eğitim modüllerinin belirlenmesi ve uygulanması gerekliliği bu çalışmanın önerisi olabilir.

Çalışmanın bir diğer önerisi ise benzer araştırmalara öncelik verilmesi, çevre farkındalığı konusunda farklı örneklemlerle benzer çalışmaların tekrarlanması ihtiyacıdır. Bu tür çalışmaların çoğalması yeşil farkındalı̆̆ın artırılmasında, çevre konusunda önemli stratejilerin belirlenmesinde etkili olacaktır. 


\section{KAYNAKÇA}

Acungil, Y., (2020). Üniversite Öğrencilerinin Çevresel Tutum ve Davranış Düzeylerini Belirlemeye Yönelik Bir Çalışma: Tokat Gaziosmanpaşa Üniversitesi Örneği. Ankara Üniversitesi SBF Dergisi, 75 (3), 997-1032.

Altıparmak, S. (2012). Üniversite Öğrencilerinin Çevreye Yönelik Tutumları. Uluslararası Hakemli Akademik Sağlık ve Tip Bilimleri Dergisi, 2 (2), 94-106.

Arslan, K. \& Kızıldağ, H.A. (2018). Üniversite Öğrencilerinin Çevre Duyarlılıklarının Çeşitli Değişkenler Açısından İncelenmesi: Buca Eğitim Fakültesi Örneği. ASOS Journal, Akademik Sosyal Araştırmalar Dergisi, 6 (84), 175-192.

Aydın, A. \& Toygar, A. (2018). Üniversite Öğrencilerinin Çevre Sorunlarına Yönelik Tutumları: Bandırma Onyedi Eylül Üniversitesi İktisadi ve İdari Bilimler Fakültesi Örneği. Uluslararası Bandırma ve Çeoresi Sempozyumu (UBS'18) Tam Metin Bildiriler Kitabı II, 2-19.

Başol, O. (2013). Yeşil İşler Sürdürülebilir Girişimlerde İnsan Onuruna Yakışır İşler ve Düşük Karbon Ekonomisi. KESAM Kırklareli Üniversitesi Ekonomik ve Sosyal Araştırmalar Merkezi. Erişim: https://www.researchgate.net/publication/305456798_YESIL_ISLER_SURDURULEBILIR_GIRISIML ERDE_INSAN_ONURUNA_YAKISIR_ISLER_VE_DUSUK_KARBON_EKONOMISI, (Erişim Tarihi: 01.03.2020).

Cohen, E., Taylor, S. \& Muller-Camen, M. HRM's Role in Corporate Social and Environmental Sustainability. SHRM Foundation's Effective Practice Guidelines Series.

Connection Research (cr), (2009). Who are the Green Collar Workers? A Definition and Taxonomy. Erişim: www.connectionresearch.com.au.

Fisk, P. (2010). Sürdürülebilir Büyüme: İnsanlar, Gezegen, Kâr. İstanbul: Mediacat Yayıncılık.

Garg, B. (2014). Human Resource-Driving Force of Sustainable Business Practices. International Journal of Innovative Research \& Development, 3 (7), 378-382.

Gregson, J.A. (2010). A Conceptual Framework for Green Career and Technical Education: Sustainability and the Development of a Green-Collar Workforce. Journal of Technical Education and Training (JTET), 2 (1), 113-126.

Gültekin, M.C. (2017). Üniversite Öğrencilerinin Çevresel Duyarlılıklarına Dair Bir İnceleme: Mardin Artuklu Üniversitesi Örneği. Selçuk Üniversitesi Sosyal ve Teknik Araştırmalar Dergisi, 14, 172-185.

Harvey, D. M., Bosco, S. M. \& Emanuele, G. (2010). The impact of "green-collar workers" on organizations. Management Research Review, 33 (5), 499-511. 
ILO (2013). Sustainable Development, Decent Work and Green Jobs. International Labour Conference, 102 ${ }^{\text {nd }}$ session, Report V, Genova. Erişim: http://www.ilo.org/wcmsp5/groups/public/---ed_norm/--relconf/documents/meetingdocument/wcms_207370.pdf.

Kanbak, A. (2015). Üniversite Öğrencilerinin Çevresel Tutum ve Davranışları: Farklı Değişkenler Açısından Kocaeli Üniversitesi Örneği. Kocaeli Üniversitesi Sosyal Bilimler Dergisi, KOSBED, 77-90.

kigem.com (2020). İnsan kaynaklarında yeşil yakalılar dönemi. Erişim: https://www.kigem.com/insankaynaklarinda-yesil-yakalilar-donemi.html (Erişim Tarihi: 23.02.2020).

Mc Clure, L. A., Le Blanc, W. G., Fernandez, C. A., Fleming, L. E., Lee, D. J., Moore, K. J. \& CabanMartinez, A. J. (2017). Green Collar Workers: An Emerging Workforce in the Environmental Sector. JOEM, 59 (5), 440-445.

Oğuz, D., Çakcı, I. \& Kavas, S. (2011). Yüksek öğretimde öğrencilerin çevre bilinci. SDÜ Orman Fakültesi Dergisi, 12, 34-39.

Ones, D. S. \& Dilchert, S. (2012). Environmental Sustainability at Work: A Call to Action. Industrial and Organizational Psychology, 5, 447-469.

Sayg1lı, M., Özdemir, A., Tanyeri, A.E. \& Erden, C. (2016). Çevre Bilinci ve Çevre Dostu Ürün Bilincine İlişkin Tutumların İncelenmesi Üzerine Bir Araştırma: Adıyaman Üniversitesi Örneği. ISEM 2016, $3^{\text {rd }}$ International Symposium on Environment and Morality, 4-6 November 2016, Alanya, Türkiye Tam Metin Bildiriler Kitabı, 1089-1098.

Sungur, Z. (2011). Türkiye'de Yeşil Yakalı Mesleklerin Gelişiminde Güncel Eğilimler. International Conference on Eurasian Economies 2011, Session 2C: Çalışma Ekonomisi, 154-159.

Şengül, Ü., Eslemian, S. \& Eren, M. (2013). Türkiye'de İstatistikî Bölge Birimleri Sınıflamasına Göre Düzey 2 Bölgelerinin Ekonomik Etkinliklerinin VZA Yöntemi ile Belirlenmesi ve Tobit Model Uygulaması. Yönetim Bilimleri Dergisi, 11(21), 75-99.

Şenyurt, A., Bayık Temel, A. \& Özkahraman, Ş. (2011). Üniversite Öğrencilerinin Çevresel Konulara Duyarlılıklarının İncelenmesi. S.D.Ü. Sağlık Bilimleri Enstitüsü Dergisi, 2 (1), 8-15.

UNEP/ILO/IOE/ITUC (2008). Green Jobs: Towards Decent Work in a Sustainable Low-Carbon World. Erişim: http:/ / www.unep.org/labour_environment/PDFs/Greenjobs/UNEP-Green-Jobs-Report.pdf. 